Note: This is the final text as submitted to the journal. It does not reflected final edits made at proofs stage. The final article is available here:

https://journals.sagepub.com/doi/full/10.1177/2041905819854309

\title{
Can democracy be done better?
}

\section{Alan Renwick and Michela Palese}

There is widespread disillusionment with the state of contemporary political discussion. Two major events in 2016 - the Brexit referendum in the UK and the presidential election in the US raised concerns to a new level, leading the Oxford Dictionaries to declare 'post-truth' their 'word of the year'. But the problems have deep roots. Public confidence in politicians, journalists, and social media companies - the main actors in political discourse - is at rock bottom. ${ }^{1}$ Democracy requires that voters be able to develop their views freely: without being subject to undue misinformation, and with access to reliable information. Yet this basic democratic requirement often goes unfulfilled.

We have therefore investigated what can be done to ensure high-quality information and discussion during election and referendum campaigns. We conducted detailed research into practices in the UK and other democracies, focusing on seven that have adopted particularly innovative approaches: Germany, the Netherlands, Ireland, Canada, the United States, Australia, and New Zealand. We have thereby identified three basic ways of addressing the problem - by confronting misinformation, promoting quality information, and promoting quality discussion each of which has its own variants. Here we outline these strategies and argue for an approach to reform that draws on them all to develop a new way of thinking about what election and referendum campaigns are for. ${ }^{2}$

\section{Definitions}

Before embarking, we need to clarify what we mean by 'high-quality' information and discussion. We define high-quality information as having four primary characteristics:

1. Accuracy: Information should be neither false nor misleading. Where there is uncertainty, that should be acknowledged.

2. Balance: Information should come from the widest possible range of perspectives and there should be appropriate balance among these.

3. Accessibility: Information should be presented in a way that is accessible to the widest possible range of citizens.

\footnotetext{
${ }^{1}$ See the Hansard Society's Audit of Political Engagement 16: The 2019 Report.

${ }^{2}$ For a more detailed account, see Alan Renwick and Michela Palese, Doing Democracy Better: How Can Information and Discourse in Election and Referendum Campaigns in the UK Be Improved? (London: Constitution Unit, 2019).
} 
4. Relevance: Information should address the issues that matter to citizens when forming their opinions and making their decisions.

High-quality discussion is rooted in high-quality information and has three further features:

1. Inclusiveness: Discussions should include as many people as possible. Their perspectives should be genuinely heard, not merely present.

2. Bridging: People of different backgrounds and perspectives should engage with each other, not just participate in discrete silos.

3. Open-mindedness: People should approach discussions with open minds and listen with respect to people with differing views.

Information and discussion need not only have these features, but also be seen to have them on all sides of the debate. Trust in those who provide information and/or promote discussion is key.

\section{Confronting Misinformation}

In our first set of strategies, official regulators, broadcasters, social media companies, and others seek to strengthen the quality of information and discourse by confronting misinformation. In their interventions, these actors react to information provided by others and seek to ensure its quality.

The bluntest such approach is simply to ban misinformation. Indeed, some advocated exactly this in the wake of the 2016 Brexit referendum. Two polities with such provisions are South Australia and New Zealand: in the former, the Electoral Commission can require campaigners to withdraw claims that it deems false and misleading; in the latter, the Advertising Standards Authority polices accuracy in all advertising, including political advertising. We found that these provisions operate effectively and are well regarded by politicians, the media and the public. But they affect the broader quality of information and discourse only at the margins. It remains all too possible for political debate to descend into confusing swirls of heavily spun accusations and counteraccusations.

Indeed, misinformation bans could not do more than that. It would be problematic in the political realm to ban anything but strictly false claims. But a misleading claim can almost always be presented in a manner that is not strictly false, so this approach cannot substantially change the tenor of debate. Furthermore, there would be major dangers if campaigners chose to 'weaponise' adverse rulings for their own purposes - for example, to claim they were under attack from the 'establishment'. Such claims have been rare in Australia and New Zealand, but reactions to some recent UK Electoral Commission rulings on the financing of Brexit referendum campaigns suggest that the environment here may be less benign.

That is not to say that milder strategies for confronting misinformation - notably, fact-checking and enhancing transparency - cannot be useful. Fact-checking exposes misinformation without 
denying people access to it, empowering voters to make up their own minds. There can be a danger that people accept only those fact-checks that fit their preconceptions, but increasing research suggests that fact-checking can be effective when appropriately delivered. Transparency, meanwhile, which allows everyone to see what messages have been targeted to whom by whom, is an important prerequisite for identifying misinformation. Concerns about lack of transparency in the digital domain have fuelled calls for measures to address this, including 'imprints' for all online political advertising and the development of an integrated political advertising archive.

Yet such strategies are merely reactive. More proactive measures for ensuring that high-quality information is widely available are also needed.

\section{Promoting Quality Information}

Voters should be able to find information that they trust and can relate to, and that answers their questions. The second set of strategies seek to promote this directly. Information can take many forms. In Figure 1, we suggest six discrete types in an 'information ladder', ranging from the most basic at the bottom to the most sophisticated at the top.

Figure 1. The information ladder

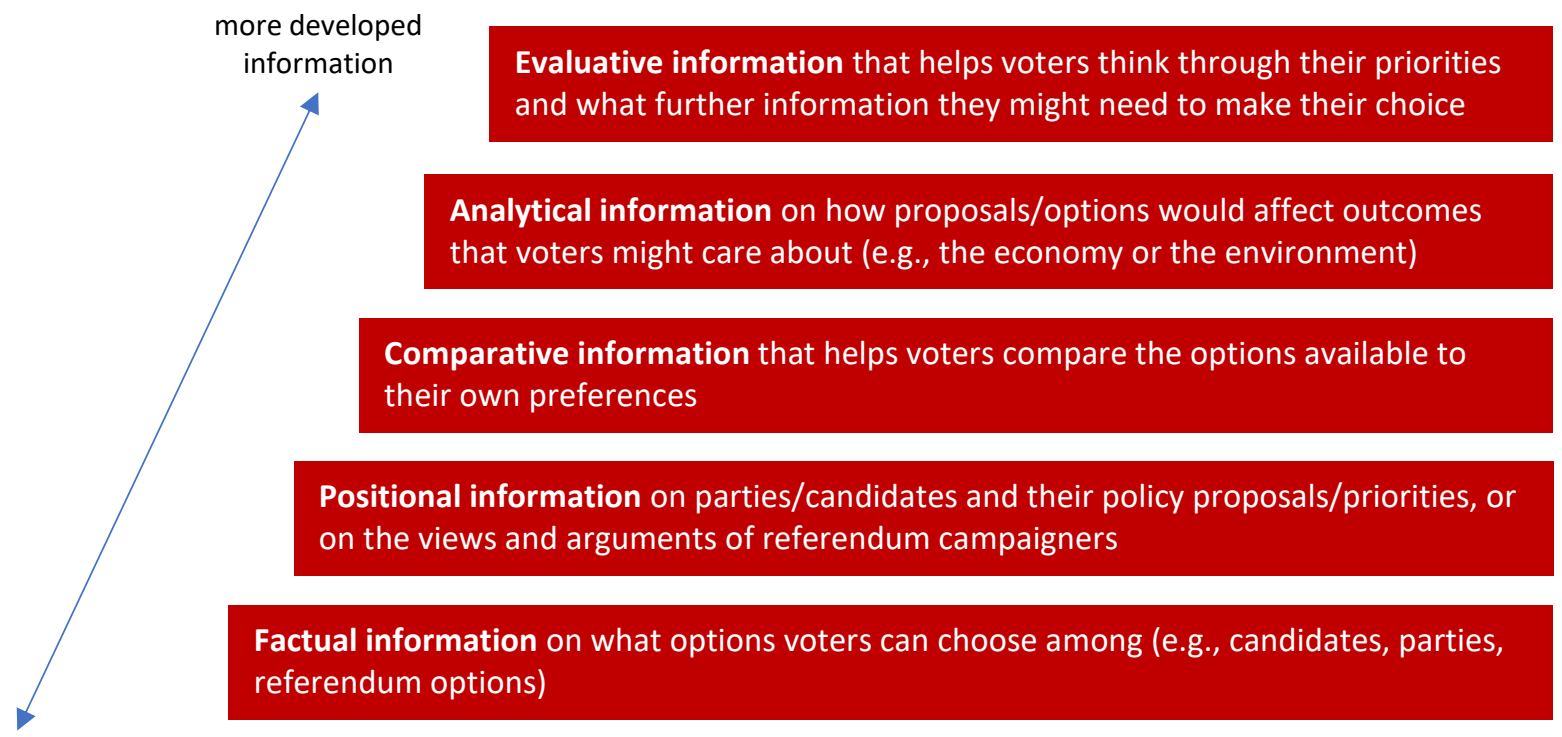

Procedural information on matters such as when, where and how to vote

We have identified four approaches to information provision in democratic polities, which reach up this ladder to different degrees.

First, 'basic' information provision is limited to the bottom two rungs of the ladder, consisting of procedural information on when, where and how to vote, and simple factual information on the 
options in the election or referendum. Provision of even this kind of information is currently patchy in the UK. Voters receive a polling card and, in referendums, a leaflet setting out the options. An Electoral Commission website helps first-time voters know what to expect at the polling station. But basic information on election candidates can be hard to find - particularly in local elections, when media attention may be limited. Building upon the work of civil society organisations in the UK and international experience, it would be relatively straightforward to improve such provision through, for example, a nationwide website allowing voters to find all their local candidates, together with biographical and other information.

Second, voting advice applications (VAAs) are online tools that allow voters to answer a range of questions on their own preferences and receive information on which parties or candidates are closest to them. They thus move up to the third and fourth rungs of the information ladder, helping voters locate their existing preferences within policy debates. VAAs have already been valuable in the UK, but have been shoestring operations. More funding would allow their content, design, and reach to be developed much further. Drawing upon international experience, particularly in Germany where the 'Wahl-O-Mat' VAA is used by millions of voters at each election, public funding for one or more VAAs in the UK could help unlock this potential.

Third, in-depth, rigorous analysis of policy proposals contained in party manifestos - information reaching the fifth rung of the ladder - can help voters work out what they think of the options on offer. Official systems for providing such information (generally considering proposals' economic and financial consequences) exist in a number of countries, most notably the Netherlands. In the UK, analysis is carried out independently, notably by the Institute for Fiscal Studies (IFS), which examines parties' tax and spending commitments. There have been proposals for the Office for Budget Responsibility (OBR) to take on a similar task, so that policy analysis could be formalised within the election process. These approaches are not mutually exclusive: indeed, there is a strong case for operating both in tandem.

A fourth and final approach to information provision relates to information in referendum campaigns. Referendums present their own challenges: they focus on a single issue, with which many voters may be unfamiliar. Many countries - including the UK, as well as Ireland, New Zealand, Switzerland, and others - therefore treat information differently in referendums. New Zealand goes furthest, offering information that extends all the way to the sixth rung of the ladder. Provision for a 2011 referendum on the voting system, for example, not only explained the options on the ballot paper, but also identified the main criteria that might be used to judge those options and assessed how each option performed in relation to each criterion. It did not tell people how much (if any) weight they should attach to each criterion - it left that for voters to decide for themselves. But it did help voters through every step towards a decision.

\section{Promoting Quality Discussion}


The strategies discussed so far conceive the enhancement of information as a largely top-down process, with little space for citizens' engagement and input in setting the agenda, developing the information, or discussing the issues. The third and final strategy, by contrast, is bottom-up. Its most ambitious form seeks to engage the mass of citizens in active deliberation. ${ }^{3}$ Given the practical challenges involved in making this work, the usual aim, more modestly, is to build information provision on the basis of deliberation by representative groups of citizens - so-called 'deliberative mini-publics' - thereby promoting trust and ensuring the information reflects regular voters' concerns.

The idea that deep deliberation among citizens should become part of our democratic practice has recently risen markedly in prominence, The 2017 Citizens' Assembly on Brexit, which one of us led, showed that it is possible for ordinary citizens to discuss even a highly polarising issue amicably, listening to each other and to experts, reflecting on their priorities, and coming to informed judgements. ${ }^{4}$ Some countries have already integrated deliberative practices within election or referendum processes: we identify two distinct models.

First, when a proposal to call a referendum is being considered, a citizens' assembly can be used to set the agenda: to discuss an issue, recommend options that ought to be pursued, and advise whether a referendum should be held on them. The most noteworthy examples of this are in Canada and Ireland - the latter being famous for its use of deliberative processes preceding the recent referendums on same-sex marriage and abortion. Both countries show that such assemblies, when designed well, deliver high-quality discussions within themselves. The Irish experience suggests that these benefits can also extend to subsequent public debate.

Second, during an election or referendum campaign, a deliberative mini-public can be used to help frame the debate on options that have already been defined. The main example of this has operated in Oregon since 2010, where, during citizen-initiated referendums, a representative panel of citizens is convened, which hears evidence on the issue in hand, deliberates, and produces a short report that is included in the information pack sent to all voters. This allows voters to see the views of fellow citizens who have had a chance to learn and think in depth. There is some evidence that such information enhances wider debate, and there is scope to develop this much further.

\section{A New Model for the UK: Reconceiving Campaigns}

We have discussed nine individual strategies above, and suggested that eight deserve to be introduced or developed further in the UK. Only the first - banning misinformation directly seems to us unwise.

\footnotetext{
${ }^{3}$ Ackerman, Bruce, and James S. Fishkin (2004). Deliberation Day. New Haven: Yale University Press.

${ }^{4}$ Renwick, Alan (2017). 'Citizens' assemblies: a better way of doing democracy?' Political Insight 8, no. 3, $24-7$.
} 
But opportunities for enhancing the quality of information and discourse in election and referendum campaigns in the UK will not be fully realised just if eight separate approaches are pursued individually. A step change in our democratic practice could be achieved through an ambitious, innovative, integrated approach that reimagines what should happen in the course of an election or referendum campaign. Rather than relying overwhelmingly on campaigners and media reactions to what campaigners say, this would place the citizen at the heart of the process, helping each voter to explore the issues and options as she or he sees fit.

Beyond incorporating the multiple kinds of information that we have discussed, we propose that such an approach should have five further key features:

1. First, the various information materials should be brought together in an information hub. This should be flexible in structure, so that voters can find their own ways into and through the material. It should be designed to be accessible and relevant to the broadest possible range of citizens.

2. Second, the material available through the information hub should come from diverse sources: it should be coordinated, but not monolithic.

3. Third, citizen deliberation should be integrated into all aspects of information provision. This includes the strategies exemplified in Canada, Ireland, and Oregon. But many further, innovative approaches are possible, integrating citizen deliberation into fact-checking, VAA development, policy analysis, and other elements.

4. Fourth, the information hub should receive public funding to ensure it has the resources to fulfil its potential.

5. Finally, it should be run by an independent public body. Emphasising that a bold shift from current practice is needed, this should be a new body with an ambitious mandate to refresh democratic practice. It should be separate from the Electoral Commission, whose functions are largely regulatory and supervisory.

This approach could be introduced in phases, starting with a range of independent initiatives promoted by broadcasters, NGOs, academics, and others, as well as official bodies, which could gradually be brought together. It could be combined with broader action to foster a democratic media culture and strengthen citizenship education.

Such an approach could help transform the quality of information and discourse during election and referendum campaigns in the UK, as well as in other democracies. Investment of this kind will be essential if the democratic system is to operate effectively and carry public confidence in the future. 